http://dx.doi.org/10.18778/7969-549-2.06

\title{
Artur Piszek
}

Samsung Electronics Polska

\section{Qualify - narzędzie rozszerzające platformę Evernote o możliwość analizy jakościowej treści}

\begin{abstract}
Streszczenie. Autor stworzył narzędzie Qualify.artpi.net rozszerzające platformę danych Evernote o możliwość analizy jakościowej treści i kodowanie danych z wywiadów w myśl zasad teorii ugruntowanej. W artykule przedstawia zalety darmowego duetu Evernote i Qualify jako alternatywy dla komercyjnych pakietów CAQDAS (takich jak NVivo) oraz wyjaśnia krok po kroku proces wprowadzania i kodowania danych. Qualify posiada także szereg unikalnych funkcjonalności przydatnych badaczom. Do najciekawszych należą zachowanie pełnego formatowania materiałów źródłowych, rozpoznawanie tekstu i możliwość kodowania treści z zeskanowanych i fotografowanych obrazów, automatyczne kolorowanie kodów oraz opcja błyskawicznego współdzielenia danych i kolaboracji ze współpracownikami w czasie rzeczywistym.
\end{abstract}

Słowa kluczowe: Evernote, CAQDA, NVivo, teoria ugruntowana, OpenCode.

\section{Wstęp}

Artur Piszek i Krzysztof Stachura w artykule Evernote: zastosowanie notatnika internetowego do badań jakościowych (2014) przedstawili platformę danych Evernote. Opisali ją jako efektywne, intuicyjne i darmowe narzędzie wspomagające organizowanie danych jakościowych, dzielenie się nimi ze współpracownikami, kodowanie, a nawet zbieranie zdjęć, nagrań czy przechwytywanie zawartości stron WWW, forów i serwisów społecznościowych do dalszej analizy.

Aplikacja wspiera pracę naukową specjalistów wielu dziedzin. Przykładowo „platforma jest niezastąpiona dla każdego nauczyciela, ponieważ w każdej dziedzinie pozwala na wieloaspektową organizację, która jest bezpieczna i elastyczna” (McNally 2014: 56), „dla pielęgniarek to świetne narzędzie, by zapisać najnowsze informacje o ochronie zdrowia, zachować artykuł naukowy do przeczytania lub nowe leki do sprawdzenia" (Wolstenholme 2014: 33), a to wszystko dlatego, że „[...] jest użyteczną aplikacją do gromadzenia, organizowania i współdzielenia informacji i pomysłów z notatek tekstowych, dokumentów, wycinków stron WWW, fotografii i obrazów" (Berkowitz 2012: 139). 
Aplikacja działa zarówno na komputerach, jak i urządzeniach przenośnych, dzięki czemu staje się niezastąpiona $w$ arsenale narzędzi badaczy terenowych, etnografów i socjologów miasta (Schepman i in. 2012; Piszek, Stachura 2014). Sposób przypisywania znaczników i kategorii do przechowywanych informacji oraz zasady funkcjonowania bazy danych przypominają profesjonalne pakiety CAQDA, takie jak NVivo, do którego autorzy wspomnianego artykułu przyrównują Evernote (Piszek, Stachura 2014).

Do słabych stron programu Evernote należy natomiast brak możliwości kodowania fragmentów tekstu (Piszek, Stachura 2014; Jan in the Pan 2013). Znaczniki można przypisywać jedynie całym notatkom, co ogranicza zastosowanie narzędzia w klasycznym procesie metodologicznym teorii ugruntowanej (Glaser, Strauss 1967; Konecki 2000).

Sposobem obejścia tej limitacji jest otwarte API (Application Interface) pozwalające na tworzenie własnego oprogramowania współpracującego z platformą Evernote (Evernote Corporation, 2014). Umożliwiło to autorowi niniejszego artykułu zaimplementowanie funkcjonalności kodowania danych z wywiadu, tak jak jest to możliwe w OpenCode czy NVivo (Niedbalski 2012; Piszek, Stachura 2014).

\section{Qualify}

Qualify jest narzędziem uzupełniającym funkcjonalność usługi Evernote o możliwość zakreślania i kodowania fragmentów tekstów. Zostało ono zbudowane jako aplikacja internetowa dostępna z poziomu witryny WWW, dzięki czemu nie wymaga procesu instalacji oraz funkcjonuje na każdym komputerze wyposażonym w przeglądarkę internetową (Google Chrome, Safari, Mozilla Firefox i Internet Explorer w aktualnych wersjach).

Jak już wspomniano, Qualify jest aplikacją korzystającą z platformy Evernote, dlatego użytkownik pragnący rozpocząć pracę będzie potrzebował kont w obu serwisach. Konto w Evernote można założyć, wchodząc na stronę Evernote.com (Evernote Corporation, 2014).

Po rejestracji w Evernote należy założyć oddzielne konto w Qualify poprzez wejście na stronę http://qualify.artpi.net i kliknięcie odnośnika Register. Po podaniu adresu e-mail i wybraniu hasła zostanie rozpoczęty proces łączenia kont Evernote i Qualify przedstawiony na ilust. 1. By móc korzystać z udogodnień programu, należy w tym kroku wybrać opcję Authorize. Warto zaznaczyć, iż Qualify, oprócz własnych danych logowania, nie przechowuje żadnych informacji pochodzących z połączonego konta Evernote, a wszystkie dane w trakcie działania aplikacji są wymieniane pomiędzy komputerem użytkownika a serwerami Evernote. 


\section{Authorize Qualify to access your account}

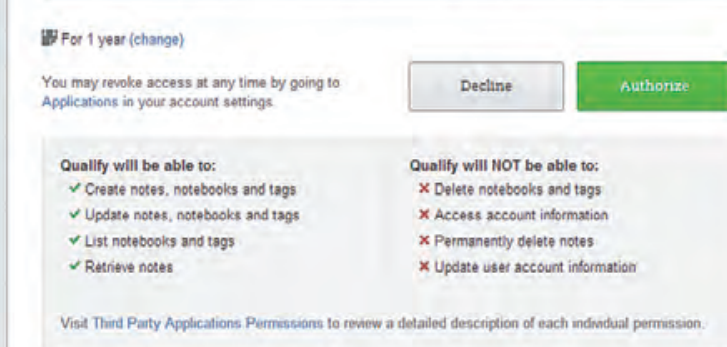

Ilustr. 1. Okno autoryzacji

Źródło: opracowanie własne

Po połączeniu kont Evernote i Qualify użytkownik zostaje przeniesiony do interfejsu programu i może rozpocząć analizę jakościową.

\section{Reprezentacja danych}

Tak samo jak w Evernote, podstawową strukturą informacji w programie jest notatka. Teksty i materiały do analizy jakościowej są notatkami wprowadzonymi do konta Evernote, natomiast adnotacje w nich utworzone za pomocą Qualify są notatkami zapisanymi w specjalnym notatniku oznaczonym Qualify.

Jak wskazali Piszek i Stachura (2014), Evernote pozwala na kategoryzowanie informacji zarówno z użyciem znaczników odpowiadających kodom w nomenklaturze teorii ugruntowanej, jak i notatników odpowiadających kategoriom, co pozwala na zbudowanie drzewiastej struktury taksonomii ułatwiającej analizę danych (Glaser, Strauss 1967; Konecki 2000; Kelle 1997).

Twórca oprogramowania Qualify musiał wziąć jednak pod uwagę, iż dane z analizy socjologicznej mogą stanowić tylko część zawartości połączonego konta Evernote i postanowił zaimplementować jedynie funkcjonalność kodowania za pomocą znaczników. Nie ogranicza to jednak badacza, albowiem w Evernote znaczniki można układać hierarchicznie, a ich funkcje są umowne. Jeśli zatem badacz potrzebuje użyć kategorii podczas kodowania, może przykładowo w Evernote utworzyć znacznik kategorie, zagnieździć w nim znaczniki obraz_programisty i znaczenie_technologii, a będzie mógł z nich korzystać w Qualify.

Dzięki takiej elastycznej strukturze znaczników można na jednym koncie Evernote gromadzić dane z wielu projektów, rozgraniczając materiał wedle uznania. Warto wspomnieć, że ze względu na ograniczenia platformy Evernote 
znaczniki nie mogą zawierać spacji, natomiast użyteczną praktyką jest używanie znaków specjalnych dla etykiet, które warto wyróżnić. Posługując się ponownie przykładem kategorii, można użyć nazw \#obraz_programisty i \#znaczenie_technologii, co sprawi, iż będą się wyświetlały obok siebie na liście znaczników.

\section{Interfejs programu}

Na samej górze okna przeglądarki użytkownik znajdzie (ilustr. 2) pasek głównego menu zawierający kolejno:

- listę rozwijaną Notebooks zawierającą wszystkie notatniki z połączonego konta Evernote,

- listę rozwijaną Tags zawierającą znaczniki (wraz z utworzonymi kodami) z połączonego konta Evernote,

- listę rozwijaną Explore code zawierającą wyłącznie kody używane w adnotacjach,

- okno wyszukiwania notatek, które po wpisaniu hasła i wciśnięciu przycisku Enter rozpocznie przeszukiwanie bazy,

- listę rozwijaną Settings zawierającą ustawienia programu,

- znacznik statusu synchronizacji informujący użytkownika o trwającym ładowaniu danych, gdzie Loading oznacza trwające pobieranie nowych informacji, a Data loaded wskazuje na zakończenie tego procesu.

Qualify Notebooks - Tags - Explore Code - Search notes... Settings - Data loaded

Ilustr. 2. Główne menu aplikacji

Źródło: opracowanie własne

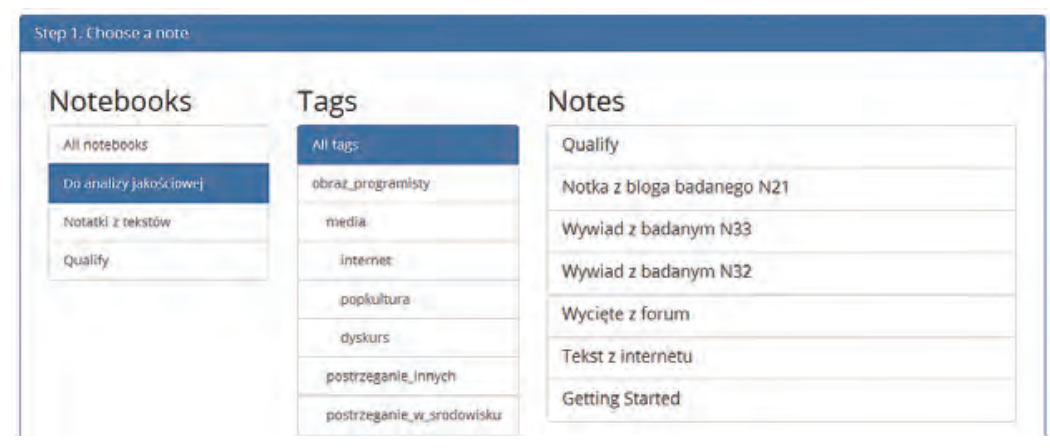

Ilustr. 3. Panel wyboru notatki

Źródło: opracowanie własne 
Poniżej głównego menu umieszczono panel wyboru notatki zatytułowany Step 1. Choose a note. Podzielono go na trzy kolumny i podobnie do górnego menu, pierwsza odpowiada notatnikom, a druga - znacznikom znajdującym się w połączonym koncie Evernote. Panel wyboru notatki przedstawia ilustr. 3.

W trzeciej kolumnie umieszczono listę notatek spełniających kryteria wyszukiwania wybrane odpowiednio z list notatników i znaczników oraz wpisane w oknie wyszukiwania. Przeszukiwanie kieruje się następującymi regułami:

1. Jeśli w polu wyszukiwania zostały użyte specjalne operatory wyszukiwania Evernote tag: albo notebook: odpowiadające odpowiednio znacznikom i notatnikom, to w procesie wyszukiwania notatek zostaną pominięte kolejne kryteria 2 i 3.

2. Jeśli został wybrany notatnik, przeszukiwanie nastąpi tylko w jego wnętrzu, w przeciwnym razie, jeśli zaznaczona została opcja All notebooks, przeszukiwanie nastąpi we wszystkich notatnikach.

3. Jeśli został wybrany znacznik, przeszukiwanie nastąpi tylko w jego wnętrzu, w przeciwnym przypadku, jeśli zaznaczona została opcja All tags, przeszukiwanie nastąpi we wszystkich znacznikach.

4. Jeśli w okno wyszukiwania został wpisany tekst, wyszukane zostaną tylko notatki zawierające ten ciąg znaków, w przeciwnym przypadku wyświetlone zostaną notatki spełniające kryteria 2 i 3.

Po wybraniu notatki z listy zawartość okna Step 1. Choose a note jest ukrywana. W każdym momencie można ją przywrócić, klikając jego nagłówek.

\section{Panel notatki}

Panel notatki, który zawiera główną funkcjonalność aplikacji, przedstawia ilustr. 4. To w nim prezentowany jest tekst, a użytkownik tworzy adnotacje i przypisuje kody.

Na samej górze panelu znajduje się tytuł kategoryzowanego tekstu, a niżej są umieszczone odnośniki:

- Open in Evernote Desktop otwiera prezentowany tekst w lokalnie zainstalowanej aplikacji Evernote, jeśli znajduje się ona na komputerze,

- Open in Evernote Web otwiera prezentowany tekst w internetowej wersji aplikacji Evernote,

- Annotations in Evernote Web otwiera wszystkie adnotacje do aktualnie prezentowanego tekstu w internetowej wersji aplikacji Evernote.

Pod tymi funkcjami znajduje się lista kodów użytych w adnotacjach do prezentowanego tekstu. Dla ułatwienia system przypisuje kolory do kodów. Po naciśnięciu nazwy kodu następuje podświetlenie adnotacji nim opisanych, a każde 
nowe zaznaczenie zostanie automatycznie zakodowane. Umożliwia to wyjątkowo szybkie kodowanie, ponieważ przypisanie kodu do fragmentu tekstu wymaga jedynie zaznaczenia i dwóch kliknięć przycisku Enter.

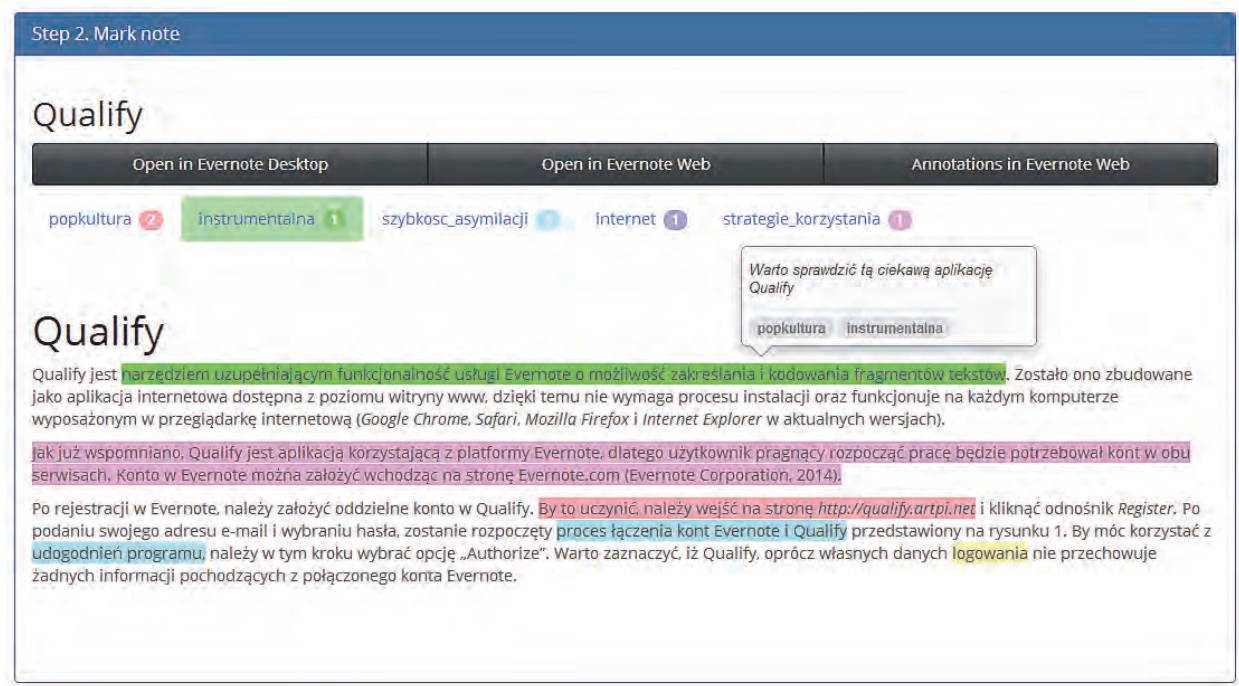

Ilustr. 4. Panel notatki

Źródło: opracowanie własne

Poniżej umieszczono zawartość analizowanego tekstu. Warto zwrócić uwagę, iż tekst jest prezentowany w tej samej formie, w której został zapisany do Evernote, z zachowaniem stylów i formatowania, co nie jest możliwe np. w aplikacji OpenCode (Niedbalski 2012).

Istnieje możliwość dokonywania poprawek i edycji poprzez Evernote (wystarczy kliknąć znajdujący się powyżej przycisk Open in Evernote Desktop albo Open in Evernote Web), a po zapisaniu zmian w Evernote i kliknięciu przycisku Odśwież w Qualify zmiany zostaną zaktualizowane. Edycja fragmentu, na którym uprzednio utworzono zaznaczenie, może skutkować brakiem możliwości wyświetlenia adnotacji w tekście ze względu na powstałe różnice pomiędzy tekstem źródłowym a adnotacją. Jednak adnotację będzie można dalej wyświetlić na koncie Evernote oraz w oknie Explore code w Qualify.

Jeśli tekst zawiera pliki, a w szczególności obrazy, w ich miejscu zostanie wstawiona ramka z tekstem opisującym typ pliku (np. image/png w przypadku obrazu lub application/vnd.openxml... w przypadku pliku MS Word).

Niezwykle ciekawą funkcjonalnością programu Evernote jest rozpoznawanie tekstu (Piszek i Stachura 2014). Jeśli serwer Evernote zdołał rozpoznać tekst prezentowany na załączonym obrazie, w ramce znajdzie się on w postaci 
transkrypcji, z możliwością zaznaczania i kodowania. W konsekwencji, by dokonać analizy jakościowej obrazów zawierających tekst (takich jak skany stron z książek lub nawet odręczne notatki), wystarczy zachować je w Evernote i otworzyć w Qualify.

Kodowanie w Qualify następuje poprzez zaznaczenie myszą fragmentu treści. Po tej czynności program wyświetla dymek, który należy nacisnąć, by pojawiło się okno wpisywania tekstu i kodów. Kody należy podawać w postaci tekstowej. Rozdzielone mogą być spacjami lub przecinkami i w konsekwencji nie mogą posiadać spacji w nazwie. Po kliknięciu przycisku Save lub Enter adnotacja jest zachowana na serwerach Evernote.

Adnotacje są wyświetlane poprzez kolorowe zakreślenia znane z papierowych form notatek. Po najechaniu myszą na podświetlony tekst ukazuje się dymek (ilustr. 5) z zawartością notatki i przypisanymi kodami. W prawym górnym rogu umieszczono odnośnik pozwalający na edycję adnotacji.

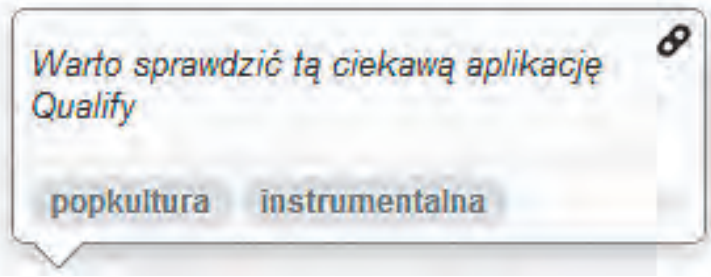

Ilustr. 5. Dymek adnotacji

Źródło: opracowanie własne

Odnośnik przenosi użytkownika do internetowej wersji Evernote, przechodząc automatycznie do notatki zawierającej adnotację. Dodając lub usuwając znaczniki, użytkownik manipuluje kodami przypisanymi do fragmentu tekstu. Może także zmienić zawartość własnego przypisu poprzez edycję tekstu znajdującego się pomiędzy napisami qNote start i qNote end. Usunięcie całej notatki skutkuje usunięciem adnotacji z Qualify.

\section{Proces kodowania}

Użytkownik pragnący rozpocząć proces kodowania danych za pomocą Qualify musi zacząć od programu Evernote. Jak wskazali Piszek i Stachura (2014), Schepman i in. (2012) oraz McNally (2014), Evernote oferuje wiele sposobów przechwytywania tekstu, począwszy od przysłania ich poprzez e-mail, a na specjalnym dodatku do przeglądarki WWW skończywszy. 
Po dodaniu tekstu do konta Evernote należy otworzyć Qualify poprzez wejście na stronę http://qualify.artpi.net i zalogować się, a ostatnim krokiem dzielącym użytkownika od analizy notatki będzie jej wyszukanie za pomocą notatnika, znaczników lub wyszukiwarki.

Gdy notatka znajdzie się już w oknie Step 2. Mark note, wystarczy zaznaczyć fragment tekstu, by dodać adnotację wraz z kodami. Po dodaniu adnotacji jest ona zachowana na serwerach Evernote.

Ciekawą możliwością może być podłączenie kilku kont Qualify do jednego konta Evernote, co skutkuje operowaniem na wspólnej bazie danych i możliwością jednoczesnej analizy tekstów. Ten sam efekt można osiągnąć poprzez udostępnianie tekstu źródłowego w Evernote za pomocą wbudowanych metod współdzielenia. W tym jednak przypadku nie wolno zapomnieć o udostępnieniu także całego notatnika zawierającego adnotacje.

Warto także pamiętać, iż konsekwencją architektury opartej na stronie WWW jest fakt, iż bez dostępu do Internetu nie będzie możliwe korzystanie z Qualify.

\section{Eksplorowanie kodów}

By ułatwić analizę zakodowanych tekstów, w programie dodano okno eksploracji kodów. Po wybraniu ze znajdującej się w głównym Menu listy Explore code wybranej pozycji, pokazywane jest podsumowanie wszystkich wystąpień danego kodu w tekstach zaprezentowane $w$ formie tabelarycznej, tak jak jest to widoczne na ilustr. 6. Po skończonej analizie okno eksploracji można zamknąć, klikając $\mathrm{x}$ znajdujący się w jego prawym górnym rogu.

\begin{tabular}{|c|c|c|c|}
\hline $\begin{array}{l}\text { Containing } \\
\text { text }\end{array}$ & Quote & Note & Tags \\
\hline $\begin{array}{l}\text { Wywiad z } \\
\text { badanym } \\
\text { N32 }\end{array}$ & Install and use Evernote everywhere & Ciekawa uwaga & $\begin{array}{l}\text { internet, } \\
\text { instrumentalna }\end{array}$ \\
\hline Qualify & $\begin{array}{l}\text { Jak już wspomniano, Qualify jest aplikacją korzystająca z platformy Evernote, dlatego } \\
\text { użytkownik pragnący rozpoczą́ pracę będzie potrzebował kont w obu serwisach. Konto w } \\
\text { Evernote można założyć wchodząc na stronę Evernote.com (Evernote Corporation, 2014). }\end{array}$ & $\begin{array}{l}\text { Badany odnosi } \\
\text { się do siebie w } \\
\text { trzeciej osobie }\end{array}$ & $\begin{array}{l}\text { internet. } \\
\text { strategie_korzystania }\end{array}$ \\
\hline
\end{tabular}

Ilustr. 6. Okno eksploracji kodu

Źródło: opracowanie własne

Istnieje także możliwość otworzenia kilku okien eksploracji naraz, dzięki czemu porównywanie zawartości oraz relacji kilku kodów staje się łatwiejsze. 


\section{Dalsze perspektywy}

Qualify został przygotowany jako aplikacja wzbogacająca Evernote o funkcje niezbędne i przydatne badaczom jakościowym. Autor niniejszego tekstu i opisywanego programu żywi nadzieję, iż aplikacja ułatwi żmudny i pracochłonny proces organizowania danych z wywiadów czy badań i pozwoli socjologom poświęcić się ważniejszym etapom pracy, takim jak analiza związków i budowanie teorii.

Badania socjologiczne, podążające za dynamiczną rzeczywistością, często ze swej natury bywają zmienne, a wspierające je narzędzia powinny za owymi zmianami podążać, dlatego autor będzie niezwykle wdzięczny za wszelkie uwagi, sugestie i pomysły dotyczące rozwoju aplikacji, które można umieszczać w specjalnym formularzu znajdującym się na stronie http://qualify.piszek.com/ support.

\section{Bibliografia}

Berkowitz Jeanne (2012), Working Together When You Can't Be Together, "American Medical Writers Association Journal", vol. 27, no. 3, s. 139-140.

Evernote Corporation (2014), Remember Everything; http://evernote.com [dostęp: 24.04.2014].

Glaser Barney, Strauss Anselm (1967), The Discovery of Grounded Theory: Strategies for Qualitative Research, Aldine Publishing Company, Chicago.

Jan in the Pan (2013), Evernote: A Guide for Academics; http://bit.ly/evernote_academia_1 [dostęp: 20.04.2014].

Kelle Udo (1997), Theory Building in Qualitative Research and Computer Programs for the Management of Textual Data, "Sociological Research Online”, vol. 2; www.socresonline.org. uk/2/2/1.html [dostęp: 11.10.2013].

Konecki Krzysztof (2000), Studia z metodologii badań jakościowych. Teoria ugruntowana, PWN, Warszawa.

McNally Eileen (2014), Evernote: A Tool for Educators, "Educational Technology", vol. 1, s. 55-57.

Niedbalski Jakub (2012), OpenCode - narzędzie wspomagajqce proces przeszukiwania i kodowania danych tekstowych w badaniach jakościowych, „Przegląd Socjologii Jakościowej”, t. 8, nr 1, s. 220-228; www.przegladsocjologiijakosciowej.org [dostęp: 4.10.2013].

Piszek Artur, Stachura Krzysztof (2014), Evernote: zastosowanie notatnika internetowego do badań jakościowych, „Przegląd Socjologii Jakościowej”, t. X, nr 2, s. 196-211; www.przegladsocjologiijakosciowej.org [dostęp: 1.06.2014].

Schepman Astrid, Rodway Paul, Beattie Carol, Lambert Jordana (2012), An Observational Study of Undergraduate Students' Adoption of (Mobile) Note-Taking Software, "Computers in Human Behavior", vol. 28, s. 308-317.

Wolstenholme Daniel (2014), Evernote app, "Nursing Standard", vol. 28, no. 19, s. 33. 


\section{Qualify - a Tool for Content Analysis of Evernote Data}

Summary. Author has created a tool called Qualify.artpi.net extending Evernote platform with text markup and qualitative data coding capability in accordance with grounded theory rules and methodology. He presents Qualify and Evernote as an alternative to commercial CAQDA Software, such as NVivo and provides step by step walkthrough of the data coding process. Qualify possesses some unique features such as preservation of source text formatting, text recognition from images and photos, automatic color-coding as well as instant data sharing and collaboration in real time.

Keywords: Evernote, CAQDA, NVivo, methodology of grounded theory, OpenCode. 